\title{
The effects of adiponectin on interleukin-6 and MCP-1 secretion in lipopolysaccharide-treated 3T3-L1 adipocytes: Role of the NF-kB pathway
}

\author{
ELENA ZOICO ${ }^{1}$, ULISSE GARBIN ${ }^{2}$, DEBORA OLIOSO ${ }^{1}$, GLORIA MAZZALI ${ }^{1}$, ANNA MARIA FRATTA PASINI $^{2}$, \\ VINCENZO DI FRANCESCO ${ }^{1}$, ANNA SEPE ${ }^{1}$, LUCIANO COMINACINI $^{2}$ and MAURO ZAMBONI ${ }^{1}$
}

Divisions of ${ }^{1}$ Geriatric Medicine; ${ }^{2}$ Internal Medicine, University of Verona, Italy

Received June 10, 2009; Accepted August 3, 2009

DOI: $10.3892 /$ ijmm_00000302

\begin{abstract}
It was recently suggested that the transcription nuclear factor- $\kappa \mathrm{B}(\mathrm{NF}-\kappa \mathrm{B})$ plays an important role in controlling the inflammation and metabolic alterations associated with obesity. In endothelial and monocytic cells, adiponectin acts as a modulator of the inflammatory response, suppressing NF- $\mathrm{\kappa B}$ activation. The aim of this study was to assess the ability of different forms of adiponectin to modulate the inflammatory response in adipocytes. 3T3-L1 preadipocytes were cultured according to standard conditions. Fully differentiated adipocytes were stimulated with $1 \mu \mathrm{g} / \mathrm{ml}$ lipopolysaccharides (LPS) for $16 \mathrm{~h}$, with or without pretreatment with $10 \mu \mathrm{g} / \mathrm{ml}$ of globular (AdG) or full-length (AdFl) adiponectin. Both AdG and AdFl significantly suppressed LPS-induced expression of IL-6 mRNA in adipocytes and reduced the concentration of IL- 6 in culture media. Adiponectin pre-treatment significantly reduced the increase in MCP-1 mRNA in adipocytes exposed to LPS. In culture media, the increase in MCP-1 detected after LPS stimulation was significantly attenuated after pre-treatment with AdG. In 3T3-L1, AdG and AdFl reduced NF- $\mathrm{KB}$ activity by 50 and $40 \%$, respectively compared to the NF- $\mathrm{KB}$ activation induced by LPS alone. Moreover, both forms of adiponectin significantly attenuated IкB- $\alpha$ as well as IKK gene expression. Pre-treatment of adipocytes with AdG or AdFl significantly increased PPAR $\gamma$ mRNA levels, taking its expression back to the basal level. Both AdG and AdFl exert anti-inflammatory activity suppressing IL-6 and MCP-1 production from inflamed adipocytes. This anti-inflammatory action may be mediated through inhibition of NF- $\mathrm{KB}$ activity as well as through increased PPAR $\gamma$ expression.
\end{abstract}

Correspondence to: Dr Elena Zoico, Division of Geriatric Medicine, Department of Surgical and Biomedical Sciences, University of Verona, Ospedale Civile Maggiore, P.le Stefani 1, I-37126 Verona, Italy

E-mail: elena.zoico@univr.it

Key words: globular adiponectin, full-length adiponectin, NF-кB, adipocyte, inflammation

\section{Introduction}

Obesity has been shown to be associated with a low grade state of inflammation, resulting from increased adipocyte activity as well as from increased macrophage infiltration of adipose tissue $(1,2)$. It has been suggested that adipocyte nuclear factor $-\kappa \mathrm{B}(\mathrm{NF}-\kappa \mathrm{B})$ plays an important role in controlling inflammation as well as the metabolic alterations associated with obesity $(3,4)$. NF- $\kappa \mathrm{B}$ activation and DNA binding is dependent on the removal of its physiological inhibitor $\kappa \mathrm{B}-\alpha(\mathrm{I} \kappa \mathrm{B}-\alpha)$ after phosphorylation by the IкB kinase complex (IKK) (5). In rats, the heterozygous deletion of IKKß, protected against the development of insulin resistance during fatty acid infusion (6). IKK mRNA expression was significantly higher in adipose tissue biopsies from insulin-resistant obese subjects than from controls (7).

Adiponectin is an abundant adipokine, mainly secreted from adipocytes with anti-atherogenic, anti-inflammatory and anti-diabetic properties (8). Its circulating levels are decreased in obesity as well as in insulin resistant states (8). Monomeric adiponectin appears to be present mainly at the adipocyte level. After association between globular domains, adiponectin is secreted into the blood stream as trimeric, hexameric and the high-molecular-weight (HMW) form (9). It has been shown that adiponectin acts as an endogenous modulator of the endothelial inflammatory response by suppressing TNF- $\alpha$ induced NF- $\mathrm{KB}$ activation in human aortic endothelial cells (10) as well as reducing the activation of IKK $\beta$ after TNF- $\alpha$ stimulation of human umbilical vein endothelial cells (11). Similarly adiponectin attenuated lipopolysaccharides (LPS)-induced increases in the release of pro-inflammatory cytokines in human (12) and porcine blood-derived macrophages (13).

It was also recently suggested that adiponectin acts as a local inflammatory regulator in adipose tissue. Both adiponectin receptor types, AdipoR1 and AdipoR2, which bind the globular and HMW forms respectively, are present in adipocytes (14). Ajuwon et al (15), showed that pre-treatment with adiponectin suppressed LPS-induced NF- $\mathrm{KB}$ activation and cytokine production in pig adipocytes. Recently we observed in subcutaneous adipose tissue biopsies of obese postmenopausal women an independent relationship between adiponectin gene expression and IкB- $\alpha$ mRNA (16). 
Despite increasing evidence that points to an antiinflammatory action for adiponectin, a few in vitro studies, conducted in endothelial (17) and monocytic cell lines $(18,19)$, produced contradictory results, and suggested that adiponectin actually has pro-inflammatory actions depending on the type of adiponectin used and the conditions of stimulation.

The aim of this study was to evaluate the ability of adiponectin to modulate the inflammatory response in 3T3-L1 adipocytes as well as to test any differences in the activity of the different forms of adiponectin.

\section{Materials and methods}

3T3-L1 adipocyte culture. 3T3-L1 pre-adipocytes (ECACCSigma-Aldrich) were grown in $5 \% \mathrm{CO}_{2}$ in D-MEM containing $10 \%$ fetal bovine serum (FBS, Bio-Whittaker Europe, Cambrex, USA), 2 mM L-glutamine and $1 \%$ penicillin-streptomycin (Sigma-Aldrich). Two days post-confluence (day 0), cells were differentiated in D-MEM with $20 \mu \mathrm{g} / \mathrm{ml}$ insulin, $0.5 \mathrm{~mm}$ IBMX and $1 \mu \mathrm{M}$ dexamethasone. After three days, fresh medium containing only insulin was added every 2 days for a further 4 days. After day 7, cells were fully differentiated and maintained overnight in D-MEM without FBS prior to stimulation. Cells were stimulated with $1 \mu \mathrm{g} / \mathrm{ml}$ LPS (SigmaAldrich) for $16 \mathrm{~h}$, with or without pre-treatment with $10 \mu \mathrm{g} / \mathrm{ml}$ mouse recombinant globular (AdG) or full-length adiponectin (AdFl) (Alexis, Axxora, San Diego, CA) for $5 \mathrm{~h}$.

Real-time PCR. Cells were washed with PBS and homogenised with QIAshredder columns (Qiagen GmbH, Hilden, Germany) prior to RNA extraction. Total RNA was recovered using the RNeasy Mini kit (Qiagen) and DNase treated (RNase Free DNase set, Qiagen). RNA quality and quantity were determined with Agilent 2100 bioanalyzer. For quantitative real-time PCR, $35 \mathrm{ng}$ of total RNA for each gene was reversed transcribed into cDNA in $20 \mu \mathrm{l}$ reactions with Iscript cDNA Synthesis (Bio-Rad, Hercules, CA, USA). Aliquots of the reverse transcriptase reaction, or water only (negative control), were PCRamplified with QuantiTect SYBR Green PCR Kit (Qiagen) and $0.3 \mu \mathrm{M}$ of pre-designed QuanTitect Primer Assays for each gene (Qiagen, $\mathrm{GmbH})$. The Entrez gene IDs were 16193 for IL-6, 21926 for TNF- $\alpha, 20296$ for MCP-1, 18035 for IкB- $\alpha$, 16150 for IKK, 19016 for PPAR $\gamma$ and 11461 for $\beta$-actin reference gene. Thermal cycling conditions for PCR reactions were $95^{\circ} \mathrm{C}$ for $15 \mathrm{~min}$ followed by 40 cycles of $94^{\circ} \mathrm{C}$ for $15 \mathrm{sec}$, $55^{\circ} \mathrm{C}$ for $30 \mathrm{sec}$ and $72^{\circ} \mathrm{C}$ for $30 \mathrm{sec}$. The abundance of each gene product was calculated by regression against a standard curve generated by 2 -fold serial dilutions of positive PCR controls for each gene. Each gene expression was normalized against $\beta$-actin. mRNA quantification was performed in triplicate for each well and tested in 3 wells for each experimental condition. Gene expression analysis was conducted by GeneX Software (Bio-Rad).

Protein analyses. The concentration of IL-6, TNF- $\alpha$ and MCP-1 in conditioned media was measured using mouse-specific ELISA kits from R\&D System (Minneapolis, USA), and from Pierce Endogen (Rockford, IL). The standard curve of each cytokine was 2000-51, 1500-23.4, 1000-16 pg/ml, respectively.
Each experimental condition was tested in 3 different wells and measured in duplicate.

$N F-\kappa B$ activity assay. Nuclear extracts were prepared using the Nuclear Extracts Kit (Active Motif Europe, Rixensart, Belgium), following the manufacturer's instructions. The nuclear pellet was resuspended in $50 \mu \mathrm{l}$ of Complete Lysis Buffer and the protein concentration was determined using the Bicinchoninic Acid Reagent Kit (Sigma Chemical Co., USA).

The immunoreactive signal produced by the binding of p65 to the NF- $\mathrm{KB}$ consensus DNA sequence (5'-GGGACTT TCC-3') was quantified in the nuclear extracts $(2 \mu \mathrm{g}$ of total protein) with a Trans-AM NF-кB p65 Chemi Transcription Factor Assay Kit, including p65 positive control.

Statistical analysis. Data are presented as means \pm SD for each experimental condition. Differences between groups were evaluated by multivariate ANOVA and Bonferroni post-hoc analysis. A P-value $<0.05$ was used to determine statistical significance. All statistical analyses were performed using the SPSS statistical package (20).

\section{Results}

The effects of $A d G$ and AdFl on the induction of proinflammatory cytokines in 3T3-L1 adipocytes. Pre-treatment with both AdG and AdFl significantly suppressed LPSinduced expression of IL-6 mRNA in mature 3T3-L1 adipocytes (Fig. 1A). Accordingly, we detected a significant increase in IL-6 levels in the culture media of 3T3-L1 adipocytes stimulated with LPS compared to the basal state (Fig. 1B). Pre-treatment of adipocytes with both adiponectin forms significantly reduced the secretion of IL-6 levels into the culture media with a more pronounced effect for AdG (Fig. 1B).

We then assessed the potential regulatory effect of adiponectin on TNF- $\alpha$ expression in 3T3-L1 adipocytes. However, in our experimental model TNF- $\alpha$ mRNA was not detected in LPS-treated adipocytes, even after prolonged stimulation (48 h) at different concentrations $(0.1,1$ and $10 \mu \mathrm{g} / \mathrm{ml})$.

A central role for macrophage infiltration has been hypothesized in adipose tissue inflammation and in obesityrelated metabolic complications. Thus, we conducted experiments to determine whether adiponectin suppresses MCP-1 expression in LPS-treated adipocytes. LPS induced a significant increase in MCP-1 mRNA expression from 3T3-L1 (Fig. 1A). Both AdG and AdFl significantly suppressed MCP-1 mRNA in LPS treated adipocytes (Fig. 1A). The significant increase in MCP-1 levels into the culture medium after LPS stimulation, was significantly attenuated only after pre-treatment with AdG (Fig. 1B).

Anti-inflammatory action of adiponectin on 3T3-L1 adipocytes. Adiponectin has been shown to disrupt the activation of $\mathrm{NF}-\kappa \mathrm{B}$ in different cell models. We therefore studied its activation by quantifying the immunoreactive binding of $\mathrm{p} 65$ to the NF-кB DNA sequence in nuclear extracts in 3T3-L1 adipocytes. In 3T3-L1 adipocytes both $\mathrm{AdG}$ and $\mathrm{AdFl}$ reduced NF- $\kappa \mathrm{B}$ activity by 50 and $40 \%$. respectively, when compared to NF- $\mathrm{KB}$ activation induced by LPS stimulation alone (Fig. 2). Moreover, after acute stimulation of adipocytes 

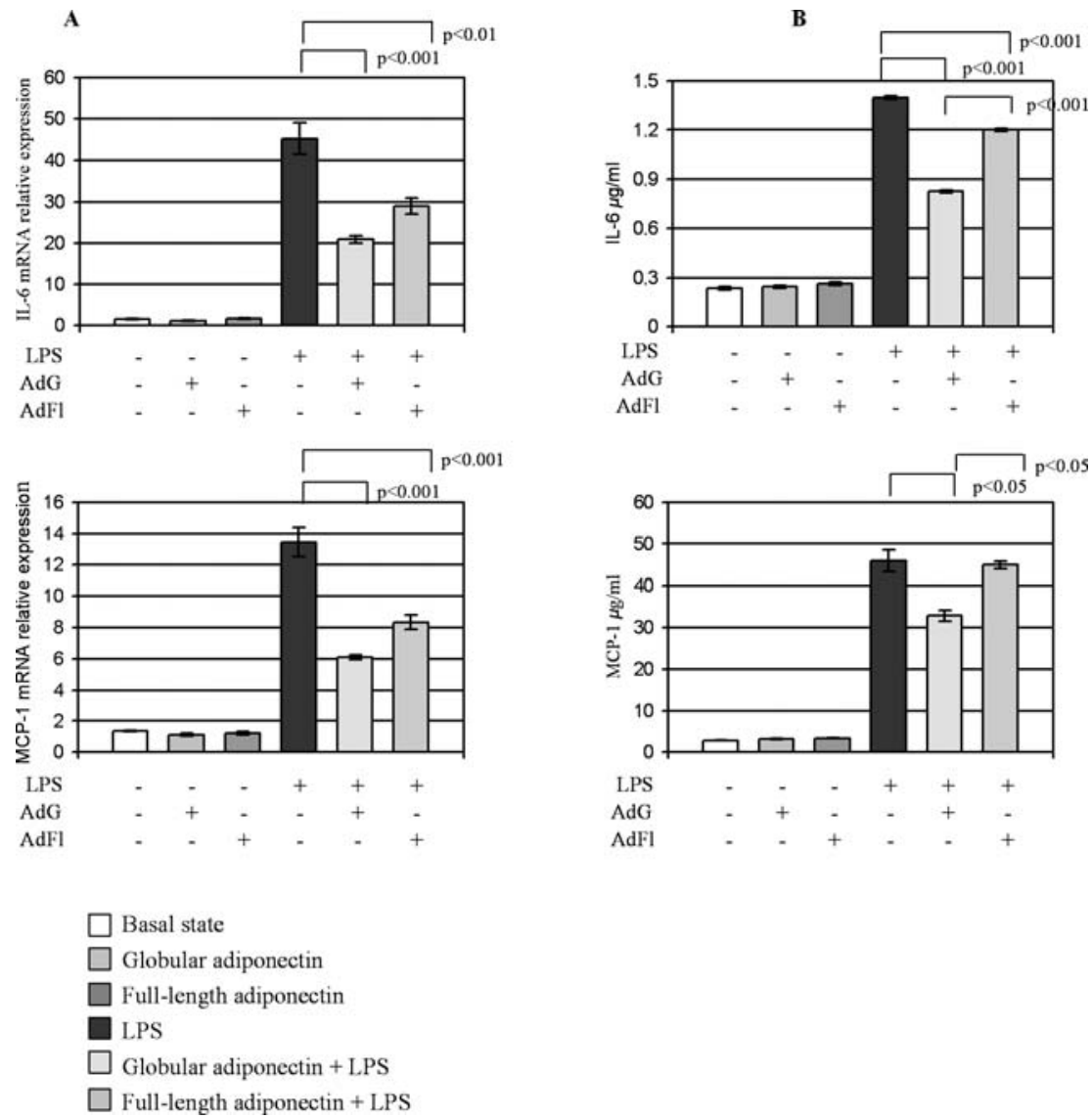

Figure 1. Effects of pre-treatment with globular and full-length adiponectin of LPS stimulated 3T3-L1 adipocytes on pro-inflammatory cytokines. (A) Relative expression of genes encoding IL-6 (top) and MCP-1 (bottom), measured by real-time PCR. (B) IL-6 (top) and MCP-1 (bottom) secretion in culture media, evaluated by ELISA. Data are presented as means \pm SD.

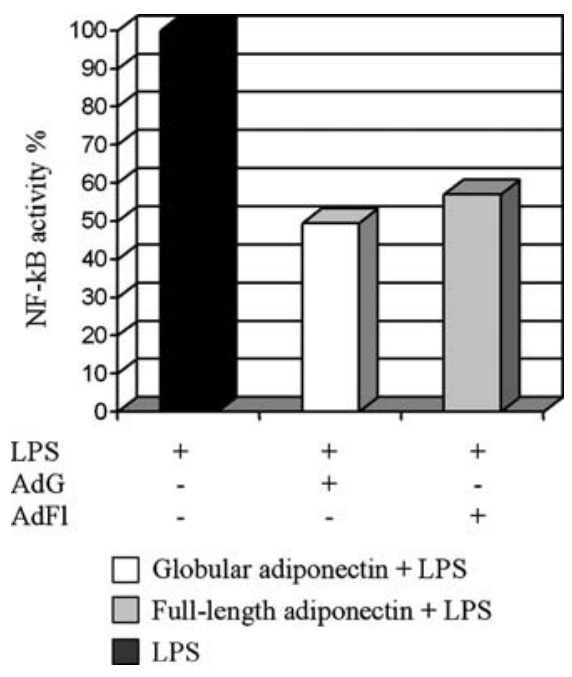

Figure 2. Effects of pre-treatment with globular and full-length adiponectin of LPS stimulated 3T3-L1 adipocytes on NFKB activity. NF-kB activity, evaluated by chemiluminescence in adiponectin pre-treated cells, was expressed as a percentage of the NF-kB activity detected in 3T3-L1 cells treated only with LPS. Data are presented as means $\pm \mathrm{SD}$.

with LPS, we observed a significant increase in IкB- $\alpha$ and IKK gene expression, significantly attenuated by pretreatment with both AdG and AdFl (Fig. 3A and B).
Because PPAR $\gamma$ exerts anti-inflammatory actions and antagonizes the transcriptional activity of NF- $\mathrm{KB}$, we tested to see if adiponectin also indirectly down-regulates NF- $\mathrm{NB}$, by increasing the expression of PPAR $\gamma$. Treating 3T3-L1 adipocytes with LPS significantly down-regulated PPAR $\gamma$ mRNA expression compared to basal levels (Fig. 4). Pretreatment of adipocytes with either AdG and AdFl significantly increased PPAR $\gamma$ mRNA taking its expression back to the basal state (Fig. 4).

\section{Discussion}

Our study supports that adiponectin has a role as a local inflammatory regulator in adipose tissue. Both AdG and AdFl exert anti-inflammatory activity by suppressing the production of IL-6 and MCP-1 from LPS stimulated 3T3-L1 adipocytes. This study also suggests that this anti-inflammatory action is mediated through direct inhibition of NF- $\mathrm{\kappa B}$ activity.

Recent evidence indicates that chronic inflammation resulting from increased adipocyte activity and macrophage infiltration of adipose tissue, plays a crucial role in the development of insulin resistance and obesity related metabolic consequences $(1,2)$. Our data show that both the mRNA and protein levels of IL- 6 and MCP-1 are consistently reduced when LPS stimulated 3T3-L1 adipocytes are pre-treated with adiponectin, expanding and complementing previous 

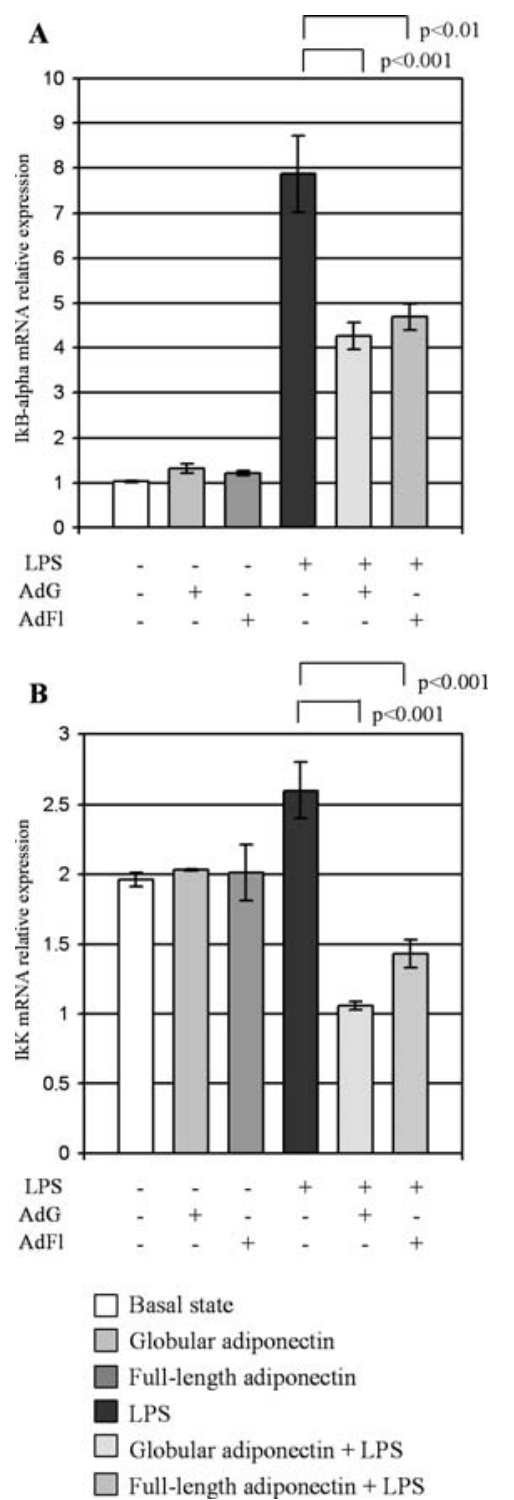

Figure 3. Effects of pre-treatment with globular and full-length adiponectin of LPS stimulated 3T3-L1 adipocytes on I $\mathrm{B}-\alpha$ and IKK mRNA. Relative expression of genes encoding IкB- $\alpha$ (A), and IKK (B), measured by real-time $\mathrm{PCR}$. Data are presented as means $\pm \mathrm{SD}$.

observations of Ajuwon and Spurlock (15) who first suggested that adiponectin has an anti-inflammatory role in adipose tissue.

MCP-1 is produced by a variety of cells including adipocytes in response to inflammatory stimuli (1). As expected, we found a significant increase in MCP-1 expression both at the mRNA and protein levels in LPS-treated adipocytes. Interestingly however, we observed a significant reduction in MCP-1 mRNA levels and protein, when LPS-stimulated adipocytes were pre-treated with adiponectin.

It has been shown that ligands of PPAR $\gamma$, the TZDs attenuate macrophage pro-inflammatory activation in vitro, by antagonizing NF- $\mathrm{KB}$ activation (21). Adiponectin has been recognized as an important mediator of PPAR $\gamma$ agonist treatment in insulin resistant subjects (22). These observations, together with our findings, suggest that TZDs suppress inflammatory events at least in part by increasing the

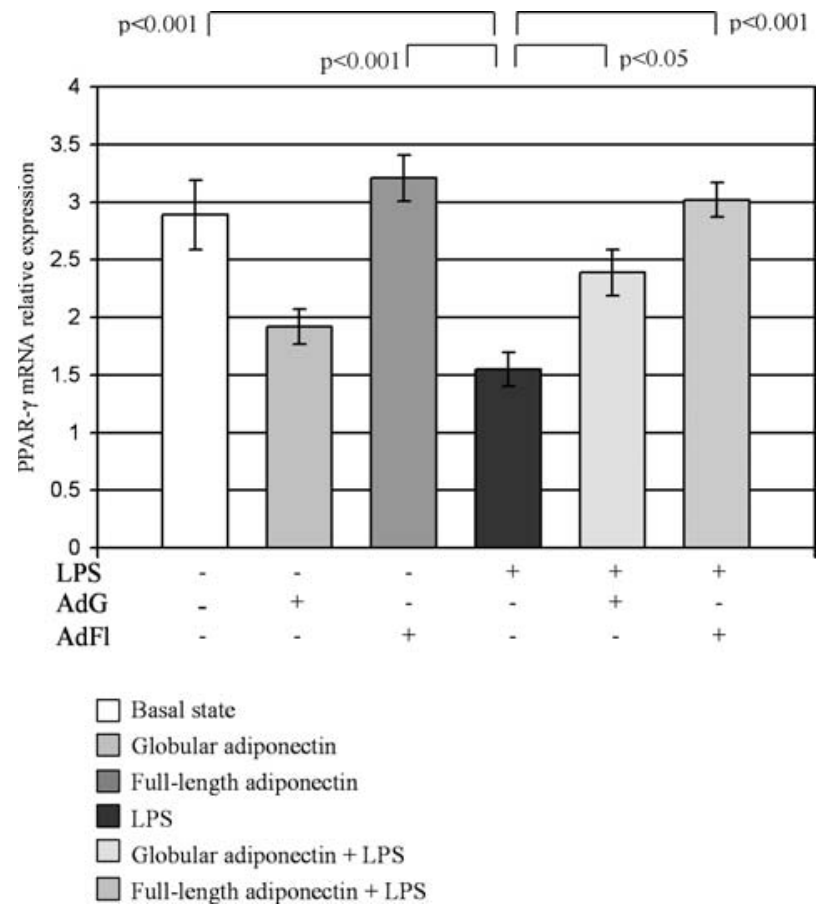

Figure 4. Effects of pre-treatment with globular and full-length adiponectin of LPS stimulated 3T3-L1 adipocytes on PPAR- $\gamma$ mRNA expression. Relative PPAR $-\gamma$ determined by real-time PCR. Data are presented as means \pm SD.

production of adiponectin which consequently reduces the secretion of MCP-1 from adipocytes, and macrophage infiltration and inflammation of adipose tissue.

Adiponectin has been shown to directly modulate the $\mathrm{NF}-\kappa \mathrm{B}$ pathway in different in vitro systems, including endothelial $(10,11,17)$ and monocytic $(12,13,18,19)$ cell lines, C2C12 myocitic cells (23) and human placenta cells (24). Our data point to the NF- $\mathrm{KB}$ system as a signalling pathway used by adiponectin to suppress cytokine production also at the adipocyte level. Moreover, we found that pretreatment with adiponectin counteracted the LPS-induced down-regulation of PPAR $\gamma$. It has been demonstrated that PPAR $\gamma$ blocks the transcriptional activity of NF- $\mathrm{KB}$ through a physical interaction (25). Thus, our findings seem to suggest that adiponectin down-regulates the NF- $\mathrm{BB}$ pathway at least in part by indirectly increasing PPAR $\gamma$ expression.

It has been suggested that the diverse biological functions of adiponectin are attributed to its different isoforms which interact with different targets and activate distinct signalling pathways (9). In our experiments we did not observe any significant difference in the anti-inflammatory activity of the two adiponectin forms, in contrast with some recent reports which suggested a pro-inflammatory action for adiponectin in endothelial $(17)$, monocytic cell lines $(18,19)$ and human placenta and subcutaneous adipose tissue explants (24).

However, our results and those of others should be considered with caution. In fact it is difficult to unequivocally interpret results obtained from very different cell systems, with very dissimilar concentrations and length of adiponectin pre-treatment used. Moreover Western blot analysis of IкB- $\alpha$ and IKK protein levels as well as determination of IKKB phosphorylation would have further confirmed our results. 
In conclusion, our experimental data indicate that adiponectin acts as a local modulator of inflammation also in adipose tissue, where it regulates the secretion of proinflammatory cytokines and chemokines as well as macrophage infiltration of adipose tissue itself. This anti-inflammatory action appears to be mediated through inhibition of NF- $\mathrm{B}$ activity as well as through increased PPAR $\gamma$ expression.

\section{Acknowledgements}

This study was supported by a grant from the MIUR project COFIN n 2005063885_005.

\section{References}

1. Xu H, Barnes GT, Yang Q, et al: Chronic inflammation in fat plays a crucial role in the development of obesity-related insulin resistance. J Clin Invest 112: 1821-1830, 2003.

2. Greenberg AS and Obin MS: Obesity and the role of adipose tissue in inflammation and metabolism. Am J Clin Nutr 83: S461-S465, 2006.

3. Sonnenberg GE, Krakower GR and Kissebah AH: A novel pathway to the manifestations of metabolic syndrome. Obes Res 12: 180-186, 2004.

4. Wellen KE and Hotamisligil GS: Inflammation, stress, and diabetes. J Clin Invest 115: 1111-1119, 2005.

5. Karin M, Yamamoto Y and Wang QM: The IKK NF-кB system: a treasure trove for drug development. Nature Rev 3: 17-26, 2004.

6. Kim JK, Kim YJ, Fillmore JJ, et al: Prevention of fat-induced insulin resistance by salicylate. J Clin Invest 108: 437-446, 2001.

7. MacLaren R, Cui W, Simard S and Cianflone K: Influence of obesity and insulin sensitivity on insulin signalling genes in human omental and subcutaneous adipose tissue. J Lipid Res 49: 308-323, 2008

8. Okamoto Y, Kihara S, Funahashi T, Matsuzawa Y and Libby P: Adiponectin: a key adipocytokine in metabolic syndrome. Clin Sci 110: 267-278, 2006.

9. Wang Y, Lam KSL, Yau Mh and Xu A: Post-translational modifications of adiponectin: mechanisms and functional implications. Biochem J 409: 623-633, 2008.

10. Ouchi N, Kihara S, Arita Y, et al: Adiponectin, an adipocytederived plasma protein, inhibits endothelial NF- $\mathrm{KB}$ signaling through a cAMP-dependent pathway. Circulation 102: 1296-1301, 2000.

11. Wu X, Mahadev K, Fuchsel L, Ouedraogo R, Xu S and Goldstein BJ: Adiponectin suppresses ІкB kinase activation induced by tumor necrosis factor- $\kappa$ or high glucose in endothelial cells: role of cAMP and AMP kinase signaling. Am J Physiol Endocrinol Metab 293: E1836-E1844, 2007.
12. Yokota T, Oritani K, Takahashi I, et al: Adiponectin, a new member of the family of soluble defense collagens, negatively regulates the growth of myelomonocytic progenitors and the functions of macrophages. Blood 96: 1723-1732, 2000.

13. Wulster-Radcliffe MC, Ajuwon KM, Wang J, Christian JA and Spurlock ME: Adiponectin differentially regulates cytokines in porcine macrophages. Biochem Biophys Res Commun 316: 924-929, 2004.

14. Kadowaki T, Yamauchi T, Kubota N, Hara K, Ueki K and Tobe K: Adiponectin and adiponectin receptors in insulin resistance, diabetes, and the metabolic syndrome. J Clin Invest 116: 1784-1792, 2006.

15. Ajuwon KM and Spurlock ME: Adiponectin inhibits LPSinduced NF- $\mathrm{\kappa B}$ activation and IL-6 production and increases PPAR $\gamma 2$ expression in adipocytes. Am J Physiol Regul Integr Comp Physiol 288: R1220-R1225, 2005.

16. Zamboni M, Di Francesco V, Garbin U, et al: Adiponectin gene expression and adipocyte NF- $\mathrm{KB}$ transcriptional activity in elderly overweight and obese women: inter-relationships with fat distribution, hs-CRP, leptin and insulin resistance. Int J Obes 31: 1104-1109, 2007.

17. Rovin BH and Song H: Chemokine induction by the adipocytederived cytokine adiponectin. Clin Immunol 120: 99-105, 2006.

18. Tsatsanis C, Zacharioudaki V, Androulidaki A, et al: Adiponectin induces TNF- $\alpha$ and IL- 6 in macrophages and promotes tolerance to itself and other pro-inflammatory stimuli. Biochem Biophys Res Comm 335: 1254-1263, 2005.

19. Haugen F and Drevon CA: Activation of nuclear factor- $\kappa B$ by high molecular weight and globular adiponectin. Endocrinology 148: 5478-5486, 2007.

20. SPSS-X User's Guide 1986. 2nd Ed. New York: McGraw-Hill, 1986.

21. Jiang C, Ting AT and Seed B: PPAR- $\gamma$ agonists inhibit production of monocyte inflammatory cytokines. Nature 391: 82-86, 1998.

22. Sharma AM and Staels B: Review: Peroxisome proliferatoractivated receptor $\gamma$ and adipose tissue-understanding obesityrelated changes in regulation of lipid and glucose metabolism. J Clin Endocrinol Metab 92: 386-395, 2007.

23. Tsao TS, Murrey HE, Hug C, Lee DH and Lodish HF: Oligomerization state-dependent activation of NF- $\mathrm{KB}$ signaling pathway by adipocyte complement-related protein of $30 \mathrm{kDa}$ (Acpr30). J. Biol Chem 277: 29359-29362, 2002.

24. Lappas M, Yee K, Permezel M and Rice GE: Release and regulation of leptin, resistin and adiponectin from human placenta, fetal membranes, and maternal adipose tissue and skeletal muscle from normal and gestational diabetes mellituscomplicated pregnancies. J Endocrinol 186: 457-465, 2005.

25. Wang $\mathrm{P}$, Anderson PO, Chen S, Paulsson KM, Sjogren $\mathrm{HO}$ and $\mathrm{Li} \mathrm{S}$ : Inhibition of the transcription factors $\mathrm{AP}-1$ and $\mathrm{NF}-\kappa \mathrm{B}$ in CD4 T cells by peroxisome proliferators-activated receptor $\gamma$ ligands. Int Immunopharmacol 1: 803-812, 2001. 